\title{
Primary Health Care Professional's Perception on the Subject of Cancer Care in Remote Area
}

\section{Priyanka Yadav}

Department of Zoology, University of Rajasthan, Jaipur, Rajasthan, India.

\begin{abstract}
Objectives: To determine perception of primary health care professional on the subject of cancer care in area with lack of facilities. Study design: Community based cross sectional survey among primary health care professionals were performe. The questionnaire included questions measuring health care professionals preferences for involvement in managing cancer patients care in terms of detection, prevention and treatment modalities and counseling about associated factors. Results: One hundred fifty-seven practicing professionals participated in the study. Majority of the respondents felt that lack of specialty and facility, motivated the health care professional to refer the cases at higher center. Half of the participant knew that screening camps in rural areas are important means of spreading the awareness in low health literacy level population. With the same perception $85 \%$ of participants felt that lack of specialization in oncology acted as barrier in treatment at primary center. Irrespective of clinical diagnosis all participants told that they are usually involved in consulting and provide psychological support to the patients. Conclusions: Health care professional do have excellent understanding about cancer care and various related factors but in view of lack of facilities and required necessary investigation in long term follow-up turn the physician choice to adopt the referral services in favors of safety of the patient. Health care professionals occupy a challenging pivotal role in clinically detection of the cancer. It is crucial that this role should be supported by providing required facilities in remote areas.
\end{abstract}

Keywords: Cancer awareness- health care professional- rural- community- India

Asian Pac J Cancer Care, 5 (1), 57-59

\section{Introduction}

Incidence of cancer is rising since past and diagnosing cancer when it is at an early stage is important, as the stage of disease at the time of diagnosis impact the survival of many cancers.

Cancer is a substantial public health problem for all population groups. However, certain subgroups, including rural communities, are more at risk than others. Published cancer statistics may not offer an accurate picture of the number of people affected by cancer in remote areas, may go undiagnosed and consequently, untreated because of the difficulties they have when attempting to access specialty health care services [1].

Primary health care professional have a key role in cancer management as the usual first point of contact for patients with potential cancer symptoms. However, there is limited work done to investigate their perceptions towards cancer. Because of this, there has been increasing
Submission Date: 11/21/2019 Acceptance Date: 01/18/2020

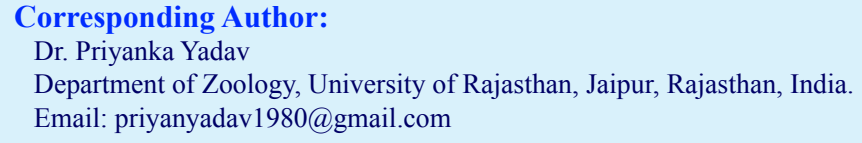

interest that what is the perception of primary health care towards cancer management? Although, data from Indian registries clearly indicate that cancer incidence rate in India are lower that the western countries but all types of cancer have been reported in Indian population including the cancers of skin, lung, breast, rectum, stomach, prostate, liver cervix, esophageal, bladder blood, mouth etc [2]. The causes of such cancer may be both internal (Genetic, mutations, hormonal, immunity) and external or environmental factors (food habits, industrialization etc [3]. There is no precise fact and figure about incidence and prevalence of cancer in particular rural areas because lack of proper reporting from rural area to cancer registries system. After knowing the facts about etiological agents it is assume that incidence and prevalence of cancer between rural and urban area have not much significant difference.

Research shows that general physicians can 
appropriately manage patient follow up compared to patients managed by outpatient oncology clinics. In reality, general physicians are better placed to holistically handle the health problem of cancer patients, which include not only the sequelae of the cancer and its treatment but often also include other issues unrelated to cancer [4]. It has long been recognized that two way communications plays a central role in providing high-quality patient care and that effective communication improves health outcomes. The most basic element of the communication is a timely, clear and complete exchange of information between the medical professionals responsible for caring for one specific cancer patient.5 General physicians based in rural and remote areas, often out of necessity, play a much greater role in coordinating care of cancer patients, clinical interventions and psychosocial care than their urban counterparts [5].

Health literacy has been recognized as a critical factor affecting the field of cancer care, from prevention and screening, to explanations of diagnoses and treatments. It may also affect cancer patients' adherence to treatment, understanding of treatment goals like curative or palliative, and health-related decision making. Cancer patients with low or moderate health literacy are at risk of poor decision outcomes and more likely to report low levels of perceived care coordination and low satisfaction with care coordination [6].

\section{Materials and Methods}

This study survey was conceived in the primary health care professional practicing in rural field area and the adjoining area of urban district of Rajasthan. The survey sample comprised views of 157 health care professionals. This study survey was done from January 2018 to April 2018. The survey design required using an approach that would yield information about perception of health care professionals in cancer care.

\section{Study Design}

Community based prospective cross sectional survey in primary health care professionals.

\section{Instruments and Techniques}

As this survey's aim was to explore the perception of cancer care in remote areas, we considered that in-depth semi-structured questionnaire based interviews with health care professionals were the most appropriate research technique to capture the information. The questionnaire was designed by the authors to find out health care professionals preferences for involvement in managing cancer patients. As no pre-existing evaluation tool was available to measure this type of questionnaire items. The questionnaire was developed with reference to the literature on the aspects of cancer care provided by health care professionals and importance of these questioned were discussed with the clinicians and academics fellow for validity and acceptability of the questionnaire items. To maximize response rates, the questionnaire was limited to one page and was designed to be completed in approximately $5 \mathrm{~min}$. Most questions were closed questions requiring responses to be ticked. Health care professionals were also invited to make comments at the end of the questionnaire.

\section{Results}

This survey investigates perception of primary health care professional in remote area and identifies common elements of practice for cancer care. To understand how cancer services are provided to rural and remote communities, it was essential to understand the insight of health care professional.

The survey sample comprised views of 157 health care professionals from Rajasthan. This study survey was done from January 2018 to April 2018. The details of responses to the pre-set 09 questionnaire are given in Table 1 .

The large majority (93\%) were regularly involved in oncology CMEs and conferences to update him regardless of number of cases seen in oncology areas.

Majority of the participants (58\%) felt that screening camps in rural areas are important means of spreading the awareness in low health literacy level population while $\sim 40 \%$ participants felt that they have no time for these activities because of heavy burden of non oncology patient load at primary center and other administrative activities.

Only $32 \%$ respondents were investigate the patients initially to approach to the cancer care while a good number of respondents $(66 \%)$ felt that lack of specialty and facility, motivated him to refer the cases at higher center. With the same thought $85 \%$ of participants felt that lack of specialization in oncology acted as barrier in treatment at primary center. Irrespective of clinical diagnosis all participants told that they are usually involved in the council part and provide psychological support to the patients.

However, it was noticeable that more than $70 \%$ of the responding primary care professionals were not involved in follow-up to the patients after referrals, because after a one or two follow-up visit, patients were become lost to follow-up.

More than half (57\%) of our participants were aware that earlier investigation at primary center have an important impact on the treatment cycle.

\section{Discussion}

The primary health care professionals hold a custodian position, referring to their role of mediating the transition of suspected malignancy cases from primary center to appropriate specialists through referral. Ensuring this is done efficiently and not unreasonably requires health care professionals to engage in thorough diagnostic workups.

In this survey health care professionals described that remote location contributed to or hindered their involvement in cancer management. Far away location from major cities and absence of specialist oncology services in rural areas as a particularly important factor for rural health care professionals who often played a more 
Table 1. Questionnaire Item for Primary Health Care Professional

\begin{tabular}{|c|c|c|}
\hline Questionnaire item & Response categories & Number of response $(\%)$ \\
\hline \multirow{4}{*}{$\begin{array}{l}\text { Have you take self initiative to update in oncology by } \\
\text { participating in }\end{array}$} & Continuing Medical education & $62(39.5)$ \\
\hline & Oncology conferences & $55(35.0)$ \\
\hline & -Workshops \& Online training & $19(12.1)$ \\
\hline & None in oncology & $21(13.4)$ \\
\hline \multirow{3}{*}{$\begin{array}{l}\text { Have you involved and take initiative for community } \\
\text { for cancer awareness by }\end{array}$} & Cancer awareness screening camps & $91(58.0)$ \\
\hline & Fund raising initiative for poor patients & $21(13.4)$ \\
\hline & -No such above activities & $45(28.6)$ \\
\hline \multirow[t]{3}{*}{ How you rate patient perception towards cancer } & -Reluctant to talk & $113(72.0)$ \\
\hline & -Patient want to talk but fearful & $25(16.0)$ \\
\hline & -Willing to discuss in details & $19(12.0)$ \\
\hline \multirow[t]{3}{*}{ How you approach to the cancer care } & -Investigate and start treatment & $13(8.3)$ \\
\hline & Investigate and refer to higher center & $41(26.1)$ \\
\hline & $\begin{array}{l}\text { Directly refer to higher center without } \\
\text { investigation }\end{array}$ & $103(65.6)$ \\
\hline \multirow{3}{*}{$\begin{array}{l}\text { Your perception about earlier investigation at primary } \\
\text { center (if available) will impact the treatment }\end{array}$} & -Yes, affect the treatment cycle & $89(56.7)$ \\
\hline & - No impact on treatment process & $22(14.0)$ \\
\hline & -No opinion & $46(29.3)$ \\
\hline \multirow[t]{3}{*}{ Which cancer would you like to investigate and treat } & Solid cancer & $113(72.0)$ \\
\hline & $\cdot$ Hematological malignancy & $7(4.5)$ \\
\hline & -No specific choice & $37(23.5)$ \\
\hline \multirow{2}{*}{$\begin{array}{l}\text { Have you council and provide psychological support to } \\
\text { the patients }\end{array}$} & $\cdot$ Yes & $157(100)$ \\
\hline & $\cdot$ No & $0(0)$ \\
\hline \multirow[t]{3}{*}{ After referring to higher center, have you follow-up to } & -Patient directly & $19(12.1)$ \\
\hline & -Specialist at higher center & $38(24.2)$ \\
\hline & -No follow-up & $100(63.7)$ \\
\hline \multirow{2}{*}{$\begin{array}{l}\text { Do you be aware of that lack of specialization in } \\
\text { oncology acted as barrier in treatment at primary center }\end{array}$} & $\cdot$ Yes & $133(84.7)$ \\
\hline & $\cdot$ No & $24(15.3)$ \\
\hline
\end{tabular}

direct role than urban professionals.

It was supposed by the research group that there was not enough response to support treatment activities for cancer.

Participated health care professionals described time constraints and non-oncology care workload as a significant barrier to delivering cancer care, as well as lack of resources at remote areas. Some of the health care professionals feel uncomfortable about providing cancer care and a perceived lack of high skill also acted as barriers to providing certain aspects of care particularly treatment care for hematological malignancy.

Increasing awareness about cancer and screening of common cancers would provide the most cost effective approach and lead to high public health potential benefits.

The role of Primary health care professionals in caring for people diagnosed with cancer in unfacilated area has focused largely on the counseling and referral, while the active treatment of many cancers is undertaken by specialists at tertiary centers.

\section{References}

1. Gary C. Doolittle \& Ashley O. Spaulding, (2006). Providing access to oncology care for rural patients via telemedicine.
J Oncol Pract. 2006 Sep; 2(5): 228-230

2. The Newsletter of NCRP, Cancer Registry Abstract, CRAB, Dec 2014, Vol-XIX, No.1

3. Imran Ali, Waseem A. Wani et al (2011). Cancer Scenario in India with Future Perspectives, Cancer Therapy 2011; Vol 8, 56-70

4. Claire E Johnson, Natalia Lizama, Neeraj Garg, et al (2012). Australian general practitioners' preferences for managing the care of people diagnosed with cancer, Asia-Pacific Journal of Clinical Oncology 2012, 1-9

5. Wolfgang Spiegel, Thomas Zidek, Heidrun Karlic et al (2010). Cancer patients' perception of information exchange between hospital-based doctors and their general practitioners. Journal of Evaluation in Clinical Practice 16 (2010) 1309-1313

6. Ana P. Martinez-Donate, Julie Halverson, Norma-Jean Simon, et al (2013). Identifying Health Literacy and Health System Navigation Needs Among Rural Cancer Patients: Findings from the Rural Oncology Literacy Enhancement Study (ROLES). J Cancer Educ. 2013 Sep; 28(3): 573-581.

This work is licensed under a Creative Commons AttributionNon Commercial 4.0 International License. 